\title{
Substantial Out-of-Pocket Health Expenditure on Prenatal Check-Ups: Estimates from a Sample of Pregnant Women in Cartagena, Colombia
}

\author{
Nelson J Alvis-Zakzuk (D) 1,2 \\ Diana Díaz-Jiménez' \\ Pablo Chaparro-Narváez (iD) \\ Juan C Gutiérrez-Clavijo' \\ Liliana Castillo-Rodríguez (iD) ' \\ Francisco Edna-Estrada (iD ${ }^{3}$ \\ Carlos Castañeda-Orjuela (iD) \\ Fernando De La Hoz-Restrepo ${ }^{4}$ \\ 'Observatorio Nacional de Salud, \\ Instituto Nacional de Salud, Bogotá, D.C., \\ Colombia; ${ }^{2}$ Departamento de Ciencias \\ de la Salud, Universidad de la Costa- \\ CUC, Barranquilla, Colombia; \\ ${ }^{3}$ Federación Colombiana de Obstetricia \\ y Ginecología, Cartagena, Bolívar, \\ Colombia; ${ }^{4}$ Grupo de Evaluación en \\ Epidemiología y Salud Pública, \\ Universidad Nacional de Colombia, \\ Bogotá, D.C., Colombia
}

Correspondence: Nelson J Alvis-Zakzuk Departamento de Ciencias de la Salud, Universidad de la Costa-CUC, Cl. 58 \#55 - 66, Barranquilla, Colombia Email nalvisI@cuc.edu.co
Objective: We aimed to estimate out-of-pocket (OOP) health expenditures and the indirect costs related to prenatal check-ups in pregnant women seen in a maternity hospital in the Colombian Caribbean region.

Methods: We described the economic costs of pregnant women, with no age limits, who attended prenatal check-ups in a maternity hospital. To estimate OOP and indirect costs owing to prenatal check-ups in pregnant women, a survey was constructed, where the woman was asked about some sociodemographic variables, to characterize those attending the prenatal check-ups. Absolute and relative frequencies, averages and confidence intervals were used to characterize the population and estimate OOP and indirect costs in pregnant women. The latter were estimated from the percentile method. A bootstrapping was performed to reduce the bias within the analysis.

Results: In total, 56 pregnant women were surveyed, with an average age of 25.9 years $( \pm 6.2)$. All women surveyed had OOP associated to the prenatal check-up in at least one costitem, and the OOP ranged between $\$ 0.3$ and \$108.7. Transportation was the item with the highest frequency of expenses, followed by food, other expenses, and drugs. The mean of OOP expenditures was $\$ 24.3$ (CI 95\% \$18.1-31.4) for women who attended their prenatal check-up.

Discussion: Considering the estimated OOP health expenditures caused by prenatal checkups by household income, women living with $<1$ minimum wage spend $7 \%$ of their income in a prenatal check-up. In women with $1-2$ and $>2-3$ minimum wages, these proportions were $5 \%, 3 \%$, respectively. Unfortunately, this makes prenatal care a significant source of economic burden, impacting poor households in Cartagena.

Keywords: out-of-pocket, cost-analysis, prenatal care, Colombia

\section{Introduction}

Diseases and mortality related to pregnancy are important issues in terms of public health. The Millennium Development Goals proposed reducing worldwide maternal mortality by $75 \%$ between $1990-2015$, and achieving universal access to reproductive health by the end of this period. ${ }^{1}$ Unfortunately, only ten countries achieved this goal, with a global reduction of $29.4 \%$, and 275,288 women dying due to causes related to pregnancy in $2015 .^{2}$

Prenatal care allows timely identification of risks in pregnancy and the prevention of complications, decreasing perinatal and maternal morbidity and mortality, newborns with low birth weight and premature births. ${ }^{3,4}$ According to the United 
Nations Children's Fund (UNICEF), only half of women around the world receive adequate prenatal care and most of those come from high-income countries. ${ }^{5}$

Maternal care is a public policy priority intended to improve pregnancy outcomes. In Colombia the Ten-Year Public Health Plan (Plan Decenal de Salud, in Spanish) seeks to guarantee four or more prenatal check-ups in $95 \%$ of Colombian pregnant women in $94 \%$ of country by 2021, and to achieve admission to prenatal care before 12 weeks of gestation in $80 \%$ of pregnancies, and to reduce maternal mortality to 150 deaths per year. ${ }^{6}$ Due to geographic, financial, organizational, and personal barriers, in Colombia not all women have timely and sufficient access to prenatal check-ups, ${ }^{3}$ resulting in inequalities in perinatal and maternal mortality. ${ }^{7,8}$

Out-of-pocket expenditure (OOP) is an important barrier to access to health services, including care for pregnant women, especially in low- and middle-income settings. ${ }^{9}$ Therefore, it is a relevant factor in research aimed at improving the guarantee of sexual and reproductive rights in the population. ${ }^{10}$ In high-income countries, the OOP health expenditures ranges between $15-25 \%$ of total health expenditures. In developing countries it varies between 25-60\%, while in Colombia, for 2016 it was $20.1 \%$, resulting in one of the Latin American countries with the lowest OOP. ${ }^{11}$

Although there are several OOP estimations for prenatal check-ups, ${ }^{9,12}$ this topic has not been widely explored in low-and middle-income settings. We aimed to estimate OOP health expenditures and the indirect costs related to prenatal check-ups in pregnant women seen in a maternity hospital in the Colombian Caribbean region.

\section{Methods}

\section{Conceptual Framework}

The economic burden of any disease is measured by three cost domains: direct costs, indirect costs and psychosocial costs. ${ }^{12}$ The studies of description and costs analysis estimate mostly direct and indirect costs. Direct costs are divided into direct medical costs and direct non-medical costs. The direct medical costs put a value on the health care resource utilization owing to the disease, at the ambulatory or hospitalized level, ${ }^{2}$ accounting for items like hospital stay, drugs, consultations, and others. ${ }^{4}$ Direct nonmedical costs are costs which support the health care process but are not directly related to it. Among these types of cost are the OOP health expenditures triggered by the disease, and that are assumed by the patient or their families. ${ }^{5,6}$ Indirect costs ${ }^{7}$ are associated with productivity losses due to illness or premature death. In an economical sense, a person's employment is a resource of great value both for themselves and for society, so the illness causes a loss of working time, temporary or permanent. ${ }^{6}$ Psychosocial costs refer to the loss of quality of life linked with having a disease; this kind of costs are difficult to quantify and methods to estimate them are not clearly standardized $^{13}$ (Figure 1).

\section{Study Design}

The present study is a cost analysis which describes the economic costs (direct non-medical and indirect) of pregnant women, with no age limits, who attended prenatal check-ups in a maternity hospital [Empresa Social del Estado Clínica Maternidad Rafael Calvo C. (ESE-CMRC)]. ESE-CMRC is a public university hospital that provides high-complex health services in gynecology-obstetrics, perinatology, and neonatology. It is considered a mother-child reference center in Cartagena de Indias ( $\sim 1$ million inhabitants) and in the northern region of the country, because it serves approximately one out of every two births in the city. In addition, it provides ambulatory services for women from Cartagena and neighboring cities (municipalities). ESE-CMRC attends mainly poor women with subsidized insurance from the Colombian Health System. This system covers $94.6 \%$ of the population, ${ }^{14}$ and comprises healthcare attention for the poor population (subsidized regime), for people who work (contributive regime), for military, teachers and others (special regime), and for those who have willingness-to-pay for private attention. ${ }^{15,16}$

\section{Participants}

Pregnant women from Cartagena and surrounding municipalities of any age who attended their prenatal check-up were consecutively included and interviewed by three researchers (NAZ, LCR, JCG) from January 22 to January 24 of 2018 in the ambulatory service of the ESECMRC. Participants were not compensated for their participation in the study.

\section{Out-of-Pocket Health Expenditures and Indirect Cost Estimation}

To estimate OOP health expenditures and indirect costs related to prenatal check-ups in pregnant women, a facility-based survey was constructed. We inquired 


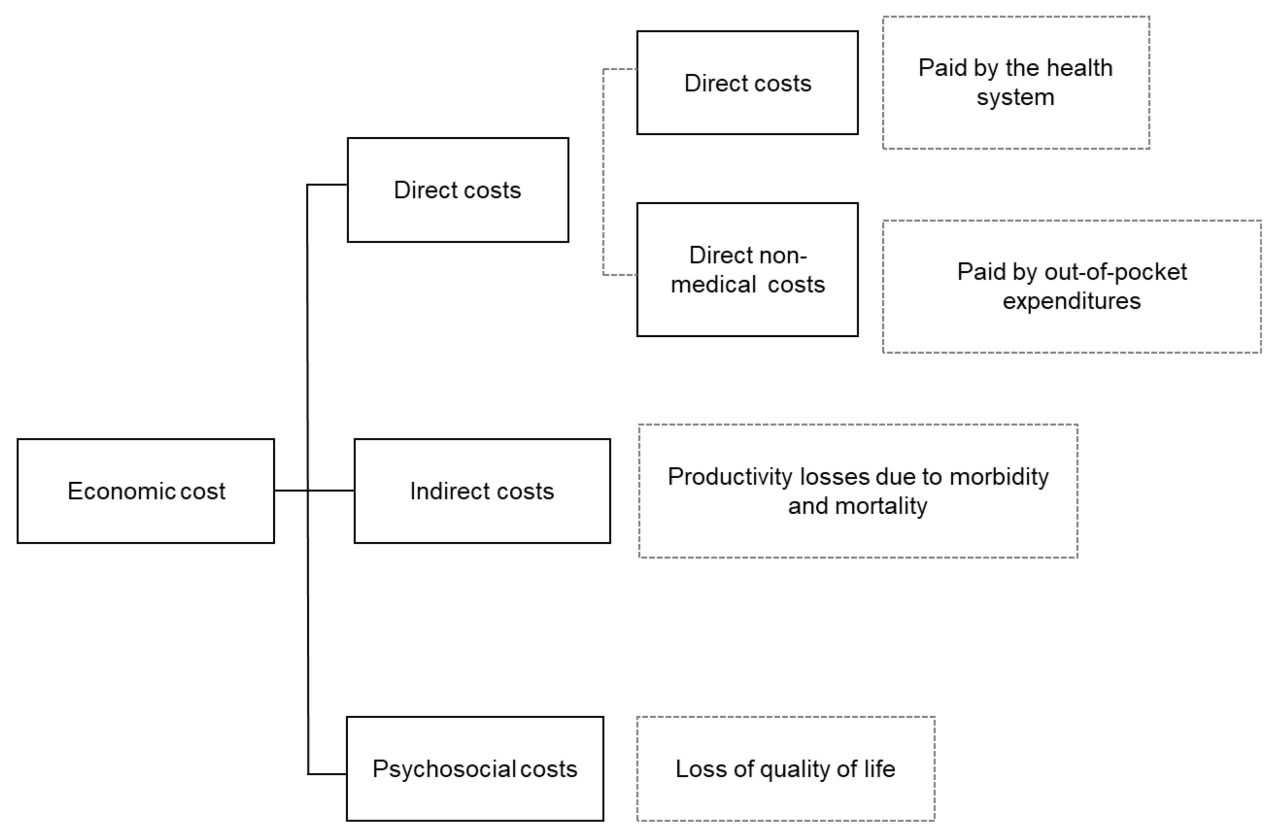

Figure I Economic costs in pharmacoeconomics. Adapted by permission from Springer Nature Customer Service Centre GmbH: Springer Nature. Journal of Cancer Survivorship Pisu M, Azuero A, McNees P, Burkhardt J, Benz R, Meneses K. The out of pocket cost of breast cancer survivors: a review. J Cancer Surviv. 2010;4:202-209. doi:10.1007/s I I764-010-0125-y, COPYRIGHT 2010. ${ }^{12}$

about marital status, date of birth, municipality of origin, socioeconomic strata of housing (the socioeconomic stratification system of Colombian households is based on the physical characteristics of the dwelling and its surroundings, classifying households into six different categories (Strata 1-6, corresponding the strata 6 to the best conditions), ${ }^{17}$ affiliation to the general system of social security in health (SGSSS, in Spanish) and level of schooling. The survey investigated how much pregnant women spend on their more recent prenatal check-up, taking into account drugs, transport, childhood services (payment to caregivers of children), co-payments, diagnostic tests, among others. In addition, we explored OOP expenses related to complications associated with pregnancy. We considered a complication as all health problems that occur during pregnancy involving any contact with the health system through an emergency consultation. We inquired as to the last complication reported by the interviewed women.

Loss of productivity was quantified due to the reduction of work time associated with the prenatal check-up. For this, we collected information from pregnant women regarding their formal or informal work activity, income, work hours lost during prenatal care and monetary income from the household. For participants with employment, we inquired about the number of work hours, losses, and costs according to their salary level. For those who did not have a formal job, as well as for housewives, the 2018 legal monthly minimum wage (LMMG) was considered as the reference standard (USD\$ 264). For those who were studying, the time of absenteeism generated by the prenatal check-up was estimated.

\section{Analysis}

We tabulated and stored each survey in a spreadsheet using a Microsoft Excel ${ }^{\circledR}$ template (Microsoft, Co.). We used absolute and relative frequencies, averages, and confidence intervals to characterize the population and estimate OOP health expenditures and indirect costs in pregnant women. The latter were estimated from the percentile method. Because we performed a convenience sampling, a bootstrapping was performed to reduce the bias within the analysis. Bootstrapping involves a re-sampling of the data obtained in a sample, with replacement, generating an empirical estimate of the complete sample distribution. It was observed that after re-sampling them, data were distributed normally (Figure 2). Item costs were described as a proportion of the average direct medical cost, accounting the average of the proportions of per-item costs. Costs were reported in American dollars using the mean exchange rate of the Central Bank of Colombia (1USD = $\$ 2,956$ Colombian pesos). ${ }^{18}$ 


\section{A Histogram of the total out-of-pocket}

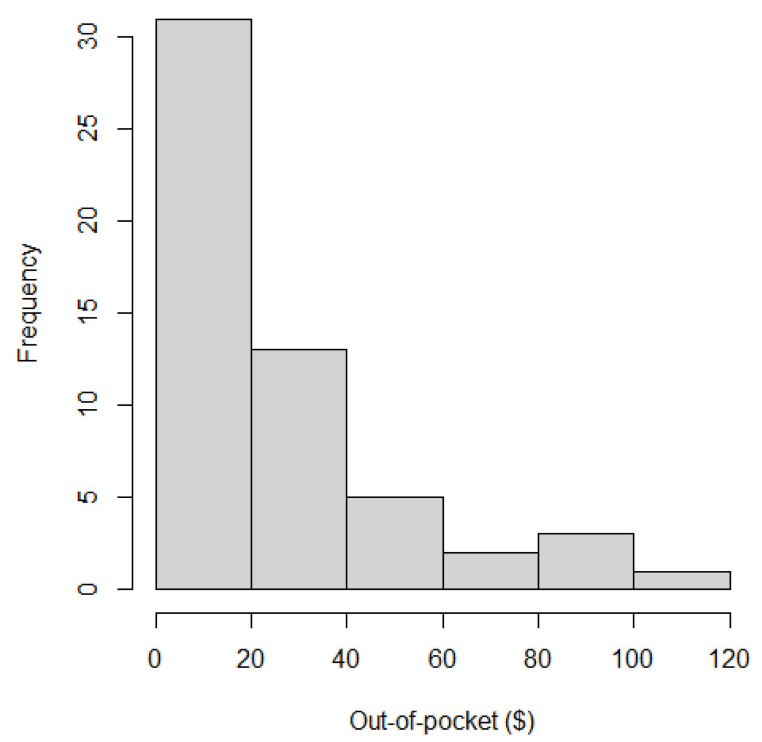

C Quantile-quantile plot of the total out-ofpocket

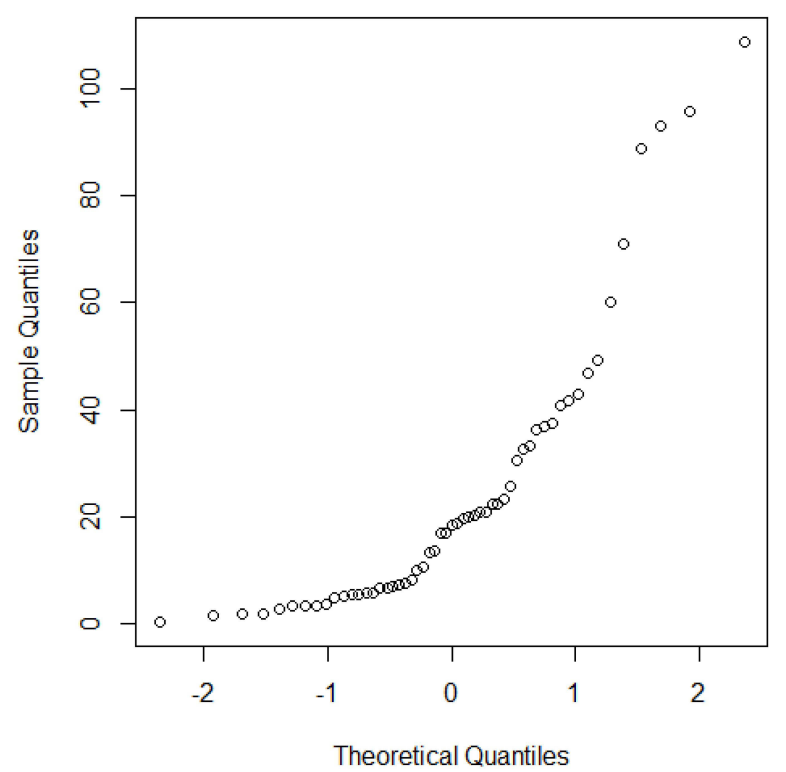

\section{B Histogram of the total out-of-pocket after bootstrapping (1,000 iterations)}

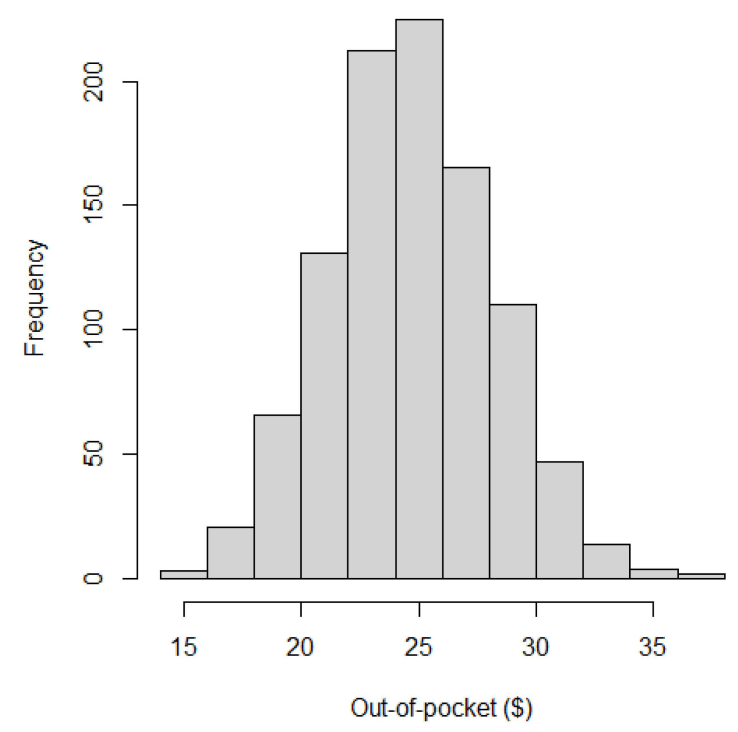

D Quantile-quantile plot of the total out-ofpocket after bootstrapping (1,000 iterations)

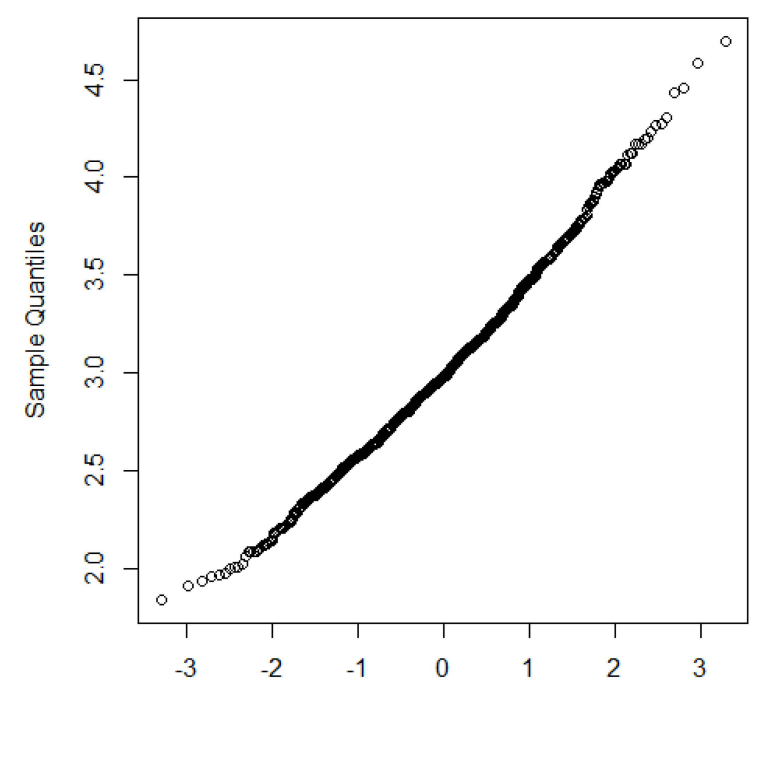

Figure 2 Histogram and quantile-quantile plot of the total out-of-pocket health expenditures related to prenatal check-ups. (A) Histogram of the total out-of-pocket. (B) Histogram of the total out-of-pocket after bootstrapping (1000 iterations). (C) Quantile-quantile plot of the total out-of-pocket. (D) Quantile-quantile plot of the total outof-pocket after bootstrapping (1000 iterations). 


\section{Ethical Considerations}

The present study is classified as having no risk for the participants, according to Resolution No. 8430 of 1993 of the Ministry of Health. ${ }^{19}$ Patients were provided with all the research information and written informed consent was requested. This study complied with the Declaration of Helsinki. Electronic and physical databases were stored only by the research team of the National Health Observatory and were of exclusive access to the researchers. This study was approved by the Institutional Review Board of Centro de Investigación para la Salud Materna, Perinatal y de la Mujer (CIMATERNA - ESE-CMRC) carried out on January 11, 2018.

\section{Results}

Table 1 gives a breakdown of the socioeconomic characteristics of pregnant women and their households, as well as the information related to their prenatal check-ups. In total, 56 pregnant women were surveyed, with an average age of 25.9 years $( \pm 6.2) .96 .4 \%$ of the respondents had completed at least primary school studies, only $7.3 \%$ were married. $75.5 \%$ of the houses where pregnant women lived were stratum 1.

One-out-of-two women reported a household income below the minimum wage. $79.1 \%$ of the women who worked before pregnancy and of those who continue working (43 in total), reported an income $<1$ LMMG and 18.6\% reported an income between 1-2 LMMG. Among the activities carried out by women before their pregnancy, most $(22,39.3 \%)$ carried out another activity, 14 (63.6\%) of those were women who studied, and the rest were engaged in housework (Table 1).

Regarding the household breadwinner, 32 pregnant women $(58.2 \%)$ reported their husbands/partners as head of their households, nine (16.4\%) stated that their mothers were the breadwinners, four (7.3\%) reported that their fathers, three $(5.5 \%)$ pregnant women considered themselves heads of their household, and seven (12.8\%) of the pregnant women reported as heads of household their grandmothers, father-in-law, or both.

According to the number of weeks of pregnancy that women had at the time of carrying out the survey, the median was 32 (range: 4-40). When asking pregnant women how many weeks of pregnancy they had when they attended the first prenatal check-up, the most common response was the third week, with 11 women $(20 \%)$.
Table I Socioeconomic Characteristics of Pregnant Women, Its Household, and Data Related to Their Pregnancy Status, 2018 $(\mathrm{n}=56)$

\begin{tabular}{|c|c|c|}
\hline Characteristic & $\mathbf{N}$ & Percentage \\
\hline \multicolumn{3}{|l|}{ Marital status } \\
\hline Free union & 47 & 85.5 \\
\hline Single & 4 & 7.3 \\
\hline Married & 4 & 7.3 \\
\hline \multicolumn{3}{|l|}{ Education } \\
\hline Technical/Technological & 22 & 40.0 \\
\hline Complete secondary & 13 & 23.6 \\
\hline Incomplete secondary & 8 & 14.5 \\
\hline Complete primary & 6 & 10.9 \\
\hline University & 4 & 7.3 \\
\hline Incomplete primary & 2 & 3.6 \\
\hline \multicolumn{3}{|l|}{ Scheme of affiliation } \\
\hline Subsidiary (poor population) & 45 & 83.3 \\
\hline Contributive & 4 & 7.4 \\
\hline Non-insured poor population & 3 & 5.6 \\
\hline Special & 2 & 3.7 \\
\hline \multicolumn{3}{|l|}{ Pre-pregnancy work } \\
\hline Worked full-time & 14 & 25.0 \\
\hline Worked part-time & 11 & 19.6 \\
\hline Not worked & 6 & 10.7 \\
\hline Occasionally worked & 3 & 5.4 \\
\hline Other & 22 & 39.3 \\
\hline \multicolumn{3}{|l|}{ Employed during pregnancy } \\
\hline No & 44 & 78.6 \\
\hline Yes & 12 & 21.4 \\
\hline Average people in the household (S.D.) & & $4.7( \pm 1.8)$ \\
\hline \multicolumn{3}{|l|}{ Household receives subsidies } \\
\hline No & 40 & 76.9 \\
\hline Yes & 12 & 23.1 \\
\hline \multicolumn{3}{|l|}{ Household income (minimum wage) } \\
\hline$<1$ & 27 & 49.1 \\
\hline $1-2$ & 18 & 32.7 \\
\hline$>2-3$ & 6 & 10.9 \\
\hline$>3-4$ & 3 & 5.5 \\
\hline$>5$ & 1 & 1.8 \\
\hline \multicolumn{3}{|l|}{ Self-perceived poverty } \\
\hline No & 39 & 69.6 \\
\hline Yes & 17 & 30.4 \\
\hline $\begin{array}{l}\text { Pregnancy and prenatal care } \\
\text { characteristics }\end{array}$ & $\mathbf{N}$ & Percentage \\
\hline \multicolumn{3}{|l|}{ Current pregnancy weeks } \\
\hline $1-18$ & 7 & 12.7 \\
\hline $19-28$ & 13 & 23.6 \\
\hline $29-35$ & 21 & 38.2 \\
\hline $36-40$ & 14 & 25.5 \\
\hline
\end{tabular}

(Continued) 
Table I (Continued).

\begin{tabular}{|l|r|r|}
\hline Characteristic & N & Percentage \\
\hline Week attended the first prenatal check- & & \\
up & & \\
I-4 & 30 & 54.5 \\
$5-10$ & 10 & 18.2 \\
II-15 & 7 & 12.7 \\
I6-30 & 8 & 14.5 \\
Number of previous pregnancies & & \\
Current & 13 & 23.2 \\
I & 21 & 37.5 \\
2 & 10 & 17.9 \\
3 & 7 & 12.5 \\
4 & 3 & 5.4 \\
5 & 2 & 3.6 \\
Pre-pregnancy co-morbidities & & \\
Yes & 1 & 1.8 \\
No & 55 & 98.2 \\
Attend prenatal check-up & & \\
Alone & 31 & 56.4 \\
Spouse & 12 & 21.8 \\
Mother & 6 & 10.9 \\
Sister & 2 & 3.6 \\
Father/mother in law & 2 & 3.6 \\
Daughter & 1 & 1.8 \\
Father & 1 & 1.8 \\
\hline
\end{tabular}

Forty $(72.7 \%)$ of the respondents attended the first prenatal check-up between week 1-10 of pregnancy. One woman did not answer this question.

All women surveyed had OOP health expenditures associated with the prenatal check-up in at least one costitem, and this expenditure ranged between $\$ 0.3-\$ 108.7$. Transportation was item with the highest frequency of expenses (56/56), followed by food (36/56), other expenses (17/56), and drugs (14/56) - Table 2 -. The mean of OOP health expenditures was $\$ 24.3$ (CI95\% \$18.1-31.4) for women who attended their prenatal checkup (Table 3). The highest percentage of OOP was spent on transportation $(39.8 \%)$, followed by food supplementary (15.4\%), and drugs (13.7\%) (Figure 3). The average OOP health expenditures related to check-ups in women living at households with an income <1 LMMG was $\$ 19.3$ (CI 9.5-29.1), women in households with 1-2 LMMG had average OOP expenses of $\$ 25.9$ (95\% CI $8.2-30.3$ ), and in those with an income of $>2-3$ LMMG expenses were $\$ 48.7$ (95\% CI 25.2-72.2) (Figure 4).

Twenty-five women presented some complication related to their pregnancy status. The mean OOP health expenditure
Table 2 Frequency of Out-of-Pocket Health Expenditures Related to Prenatal Check-Ups and Complications, 2018

\begin{tabular}{|c|c|c|c|c|}
\hline \multirow[t]{2}{*}{ Item } & \multicolumn{2}{|c|}{ Prenatal Check-Up } & \multicolumn{2}{|c|}{ Complication } \\
\hline & $\mathbf{N}$ & (\%) & $\mathbf{N}$ & (\%) \\
\hline Transportation & 56 & 100.0 & 25 & 100.0 \\
\hline Bus & 34 & 60.7 & 8 & 32.0 \\
\hline Taxi & 16 & 28.6 & 12 & 48.0 \\
\hline Moto-taxi & 8 & 14.3 & 2 & 8.0 \\
\hline Food & 36 & 64.3 & - & - \\
\hline Others & 17 & 30.4 & II & 44.0 \\
\hline Drugs & 14 & 25.0 & 7 & 28.0 \\
\hline Diagnostic tests & 13 & 23.2 & I & 4.0 \\
\hline Food supplementary & 13 & 23.2 & I & 4.0 \\
\hline Lab. Tests & 4 & 7.1 & - & - \\
\hline Childcare services & 8 & 14.3 & 3 & 12.0 \\
\hline Co-pays & I & 1.8 & - & - \\
\hline Total & 56 & 100.0 & 25 & 100.0 \\
\hline
\end{tabular}

Notes: Surveys applied to pregnant women. ESE-CMRC.

Table 3 Out-of-Pocket Health Expenditures Related to Prenatal Check-Ups and Complications, 2018

\begin{tabular}{|l|r|r|r|r|}
\hline \multirow{2}{*}{ Item } & \multicolumn{2}{|c|}{ Prenatal Check-Up } & \multicolumn{2}{c|}{ Complication } \\
\cline { 2 - 5 } & Average & \multicolumn{1}{c|}{ Cl95\% } & Average & \multicolumn{1}{c|}{ Cl95\% } \\
\hline Transportation & $\$ 9.65$ & $(7.19-12.48)$ & $\$ 11.86$ & $(5.91-20.64)$ \\
\hline $\begin{array}{l}\text { Food } \\
\text { supplementary }\end{array}$ & $\$ 3.73$ & $(2.78-4.82)$ & $\$ 0.22$ & $(0.11-0.39)$ \\
\hline Food & $\$ 3.33$ & $(2.48-4.30)$ & & \\
\hline Drugs & $\$ 2.47$ & $(1.84-3.20)$ & $\$ 2.92$ & $(1.46-5.08)$ \\
\hline Diagnostic tests & $\$ 2.45$ & $(1.83-3.17)$ & $\$ 0.22$ & $(0.11-0.38)$ \\
\hline Others & $\$ 1.31$ & $(0.98-1.69)$ & $\$ 3.40$ & $(1.70-5.92)$ \\
\hline $\begin{array}{l}\text { Childcare } \\
\text { services }\end{array}$ & $\$ 0.61$ & $(0.45-0.79)$ & $\$ 0.83$ & $(0.42-1.45)$ \\
\hline Lab. Tests & $\$ 0.65$ & $(0.48-0.83)$ & & \\
\hline Co-pays & $\$ 0.06$ & $(0.04-0.07)$ & & \\
\hline Total & $\$ 24.26$ & $(18.1-31.4)$ & $\$ 19.46$ & $(9.70-$ \\
\hline
\end{tabular}

Notes: Surveys applied to pregnant women. ESE-CMRC.

associated with a complication of pregnancy was $\$ 19.5$ (CI95\% \$9.7-33.9), and the item that represented a greater weight in this average was transportation to an emergency 
100
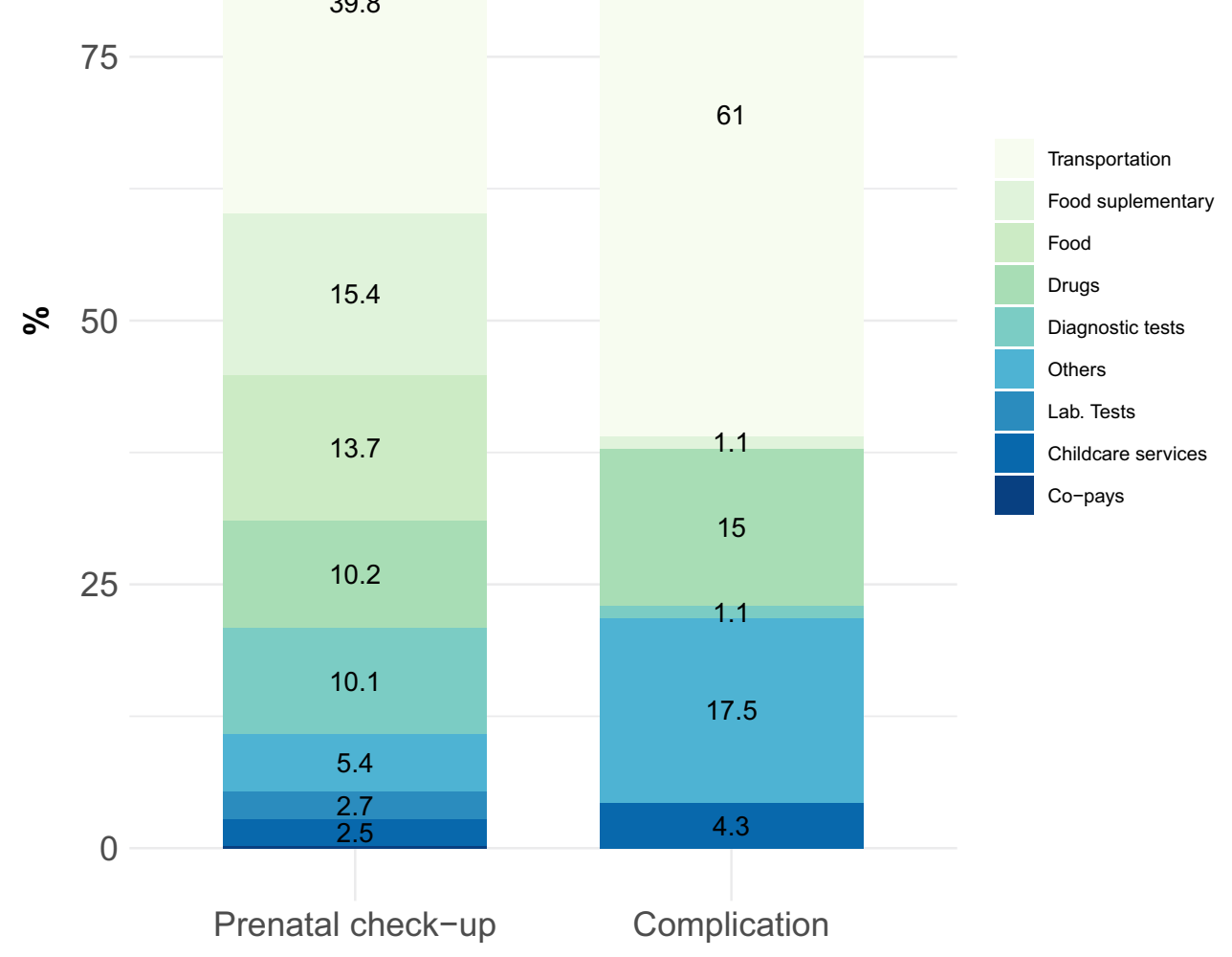

Figure 3 Distribution of the out-of-pocket health expenditures related to prenatal check-up and pregnancy complications.

service/hospital to address this complication (61\%), followed by others (17.5\%) (Figure 3). Transportation was the item with the highest frequency of expenses associated with the complications (25/25), followed by other expenses (11/25), and drugs (7/25) - Table 2.

One woman reported an average of 4.2 hours (range 112) attending the prenatal check-up. Also, their partners spent 4.5 hours (range 1-13). These, translated in terms of productivity losses, meant that a woman lost on average \$ 4.6 (CI95\% \$2.8-5.5) and her companion lost $\$ 4.9$ (range $\$ 2.7-6.6)$.

\section{Discussion}

To the best of our knowledge, this is one of the first studies conducted in Colombia that attempts to approach the knowledge of OOP health expenditures and indirect costs related to the prenatal check-ups. It was found that, despite the assurance to the SGSSS, attending a prenatal check-up can trigger OOP expenses for pregnant women and relatives of $\$ 24.3$ (CI95\% \$18.1-31.4). In addition, productivity losses produced by the time spent attending prenatal care ranged between $\$ 2.8-5.5$.

Several thresholds to establish catastrophic health expenditure (CHE) have been previously defined, ranging from $10-40 \% .^{20,21}$ CHE can indicate not only whether families have fallen into a catastrophic situation owing to high health-care costs, but also the equity of health care financing. ${ }^{22,23}$ Considering the estimated OOP health expenditures caused by prenatal check-ups by household income, we found that women living with $<1$ LMMG spend $7 \%$ of their income in a prenatal check-up. In women with 1-2 LMMG, this proportion was 5\%, and in those with a household income of $>2-3 \mathrm{LMMG}$, this percentage was $3 \%$. These proportions are similar to those estimated in the study conducted by Myint in Myanmar. ${ }^{22}$ Our findings unfortunately show that prenatal 


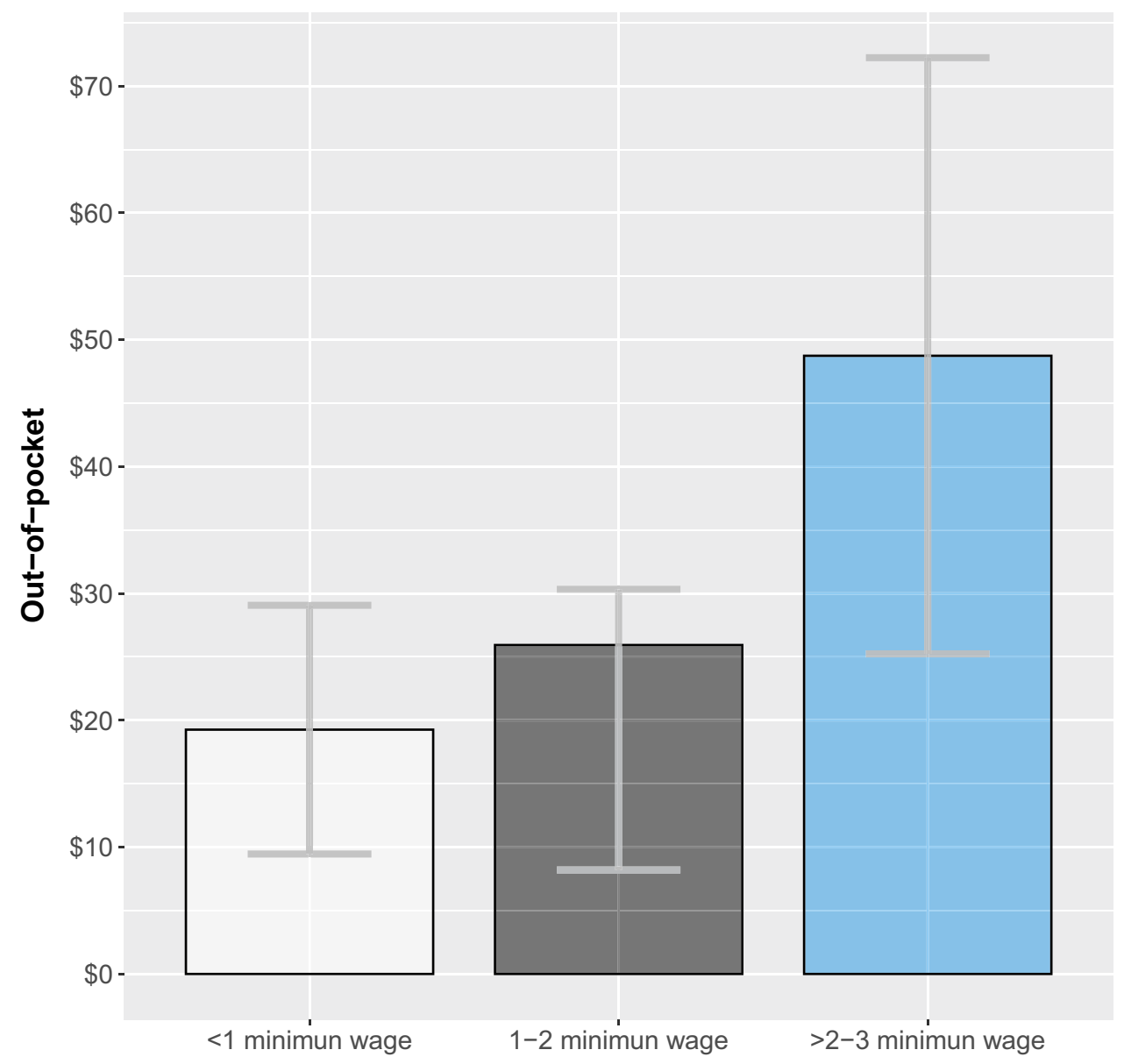

Figure 4 Out-of-pocket health expenditures related to prenatal check-ups by household income level, 2018.

care represents an important source of economic burden, impacting poor households in Cartagena, Colombia.

According to the World Health Organization and UNICEF, a woman must have coverage of at least four prenatal check-ups. ${ }^{5}$ In Colombia it is recommended to perform the first prenatal check-up in the first trimester, ideally before week $10 .^{24} \mathrm{~A}$ prenatal check-up program with a reduced number of appointments is not recommended because it is associated with an increase in perinatal mortality. ${ }^{24}$ In terms of the results of our study, most (72.7\%) pregnant women surveyed said they attended the first prenatal check-up before week 10, as recommended in the Guide. However, it is worrying that the rest of the pregnant women who sought prenatal care after week 10 , especially those (14.5\%) who requested it between week 16 and 30. Although prenatal care practices and organization may vary country by country, ${ }^{25}$ it is well documented that early participation in programs of prenatal care is generally considered to promote favorable pregnancy outcomes. ${ }^{26}$
Cost-analyses are important tools that allow quantifying the different activities that are carried out to treat or prevent a disease. ${ }^{27,28}$ They are useful because they provide the necessary inputs to make informed decisions in public health. Our results are very useful because they describe from the perspective of the patients and their families how expensive prenatal check-ups can be.

The present work has limitations. The selected women only represent information for pregnant women belonging to households located in socioeconomic strata 1, 2 and 3 (poor households). However, they would represent a large proportion of the population of Cartagena, since $91 \%$ of households belong to these three socioeconomic strata. ${ }^{29}$ In addition, about 268,000 people in the city live in poverty, and almost 35,000 in extreme poverty. ${ }^{30}$ Another limitation pertains to the convenience sampling we used. This non-probability sampling has several constraints due to the subjective nature in choosing the sample and thus it is not a good representative of the population. ${ }^{31}$ However, 
we wanted to focus especially on the poor population, so we would not have expected remarkable differences among women seeking care at ESE-CMRC.

This study has revealed questions that become new research areas for future work. For example, why should some pregnant women be spending a considerable amount of money on food supplements, laboratory tests, diagnostic tests, and medications, when pregnant women are a priority for the Colombian health system?

According to Amartya Sen, equity in the financing of health systems implies generating conditions so that individuals, regardless of their socioeconomic status and personal beliefs, gain access to goods and services that allow them to maintain their health, realize their aspirations, and achieve a well-being compatible with the development of the society in which they live. ${ }^{32,33}$ With this in mind, the results of the study lead us to recommend the inclusion of OOP as an underlying factor of public health policies related to maternal care, particularly when it constitutes an indicator of equity in access to health care services. Although at the level of public health policy the care of the pregnant woman and her prenatal check-ups are a priority, we observed how OOP health expenditures in certain areas constitute an important economic burden for them and their households. Poor households seeking to reduce the cost of attending a prenatal check-up may adhere entirely to these types of promotion and prevention measures.

\section{Acknowledgments}

We would like to thank Mark Javier Makepeace for editing and reviewing this manuscript for English language. Preliminary estimates of this study were presented at Virtual ISPOR conference, May $18-20$ of $2020 .^{34}$

\section{Disclosure}

The authors report no conflicts of interest in this work.

\section{References}

1. Organización Mundial de la Salud. ODM 5: mejorar la salud materna; 2018. Available from: https://www.who.int/es/news-room/fact-sheets/ detail/millennium-development-goals-(mdgs). Accessed January 6, 2022.

2. GBD 2015 Maternal Mortality Collaborators. Global, regional, and national levels of maternal mortality, 1990 - 2015: a systematic analysis for the Global Burden of Disease Study 2015. Lancet. 2016;388:1775-1812. doi:10.1016/S0140-6736(16)31470-2

3. Cáceres-Manrique FDM. El control prenatal: una reflexión urgente. Rev Colomb Obstet Ginecol. 2009;60(2):165-170. doi:10.18597/ $\operatorname{rcog} .342$
4. Sánchez-Nuncio HR, Pérez-Toga G, Pérez-Rodríguez P, VázquezNava F. Impacto del control prenatal en la morbilidad y mortalidad neonatal [Impact of the prenatal care in the neonatal morbidity and mortality]. Rev Med Inst Mex Seguro Soc. 2005;43(5):377-380.

5. UNICEF. Antenatal care. Available from: https://data.unicef.org/ topic/maternal-health/antenatal-care/.

6. Ministerio de Salud y Proteccion Social. Plan Decenal de Salud Pública Colombia PDSP 2012-2021. [Ministry of Health and Social Protection. Ten-Year Public Health Plan Colombia PDSP 2012-2021]. Bogotá D.C: Ministerio de Salud y Protección Social; 2013.

7. Sandoval-Vargas Y, Eslava-Schmalbach J, Quiroga-Villalobos EF, Pinzón-Villate GY. Inequidades en mortalidad materna por departamentos en Colombia para los años (2000-2001), (2005-2006) y (2008-2009) [Inequities in maternal mortality by departments in Colombia for the years (2000-2001), (2005-2006) and (2008-2009)]. Rev Salud Pública. 2013;15(4):577-589.

8. Nájera Arregocés S, Tuesca Molina R. Desigualdades y características sociodemográficas de la mortalidad materna. Rev Panam Salud Publica [Inequalities and sociodemographic characteristics of maternal mortality in La Guajira, Colombia, 2010-2012]. 2015;37(4):239-244.

9. Vian T, Feeley FG, Domente S, Negruta A, Matei A, Habicht J. Barriers to universal health coverage in Republic of Moldova: a policy analysis of formal and informal out-of-pocket payments. BMC Health Serv Res. 2015;15. doi:10.1186/s12913-015-0984-z

10. Govil D, Purohit N, Gupta SD, Mohanty SK. Out-of-pocket expenditure on prenatal and natal care post Janani Suraksha Yojana: a case from Rajasthan, India. J Health Popul Nutr. 2016;35(15):1-11. doi:10.1186/s41043-016-0051-3

11. Ministerio de Salud y Protección Social. Cifras Financieras Del Sector Salud. Notas Conceptuales y Metodológicas Sobre La Medición Del Gasto de Bolsillo En Salud [Financial data of the Health Sector. Conceptual and Methodological Notes on the Measurement of Out-of-Pocket Expenditure on Health]. Vol. 2357. Bogotá D.C.: Ministerio de Salud y Protección Social; 2015.

12. Pisu M, Azuero A, McNees P, Burkhardt J, Benz R, Meneses K. The out of pocket cost of breast cancer survivors: a review. J Cancer Surviv. 2010;4:202-209. doi:10.1007/s11764-010-0125-y

13. Palmquist RB. Valuing localized externalities. In: Revealed Preference Approaches to Environmental Valuation Volumes I and II. Routledge; 2020:81.

14. Ministerio de Salud y Protección Social. Comportamiento del aseguramiento [Behavior of the assurance]; 2018. Available from: https://www.minsalud.gov.co/proteccionsocial/Regimensubsidiado/ Paginas/coberturas-del-regimen-subsidiado.aspx. Accessed January 6, 2022.

15. Guerrero R, En MC, Isabel Gallego A. Sistema de salud de Colombia [Health system in Colombia]. Vol. 53. Salud Pública de México; 2020. Available from: https://saludpublica.mx/index.php/spm/article/ view/5036. Accessed January 6, 2022.

16. Instituto Nacional de Salud - Observatorio Nacional de Salud [National Health Observatory]. Acceso a Servicios de Salud en Colombia [Health system in Colombia]. Bogotá, DC: Décimo Prim Inf Técnico; 2019.

17. Cantillo-García V, Guzman LA, Arellana J. Socioeconomic Strata as Proxy Variable for Household Income in Transportation Research. Evaluation for Bogotá, Medellín, Cali and Barranquilla. DYNA; 2019.

18. Banco de la República de Colombia. Tasa Representativa del Mercado (TRM) [Representative Market Rate (TRM)]; 2020. Available from: https://www.banrep.gov.co/es/estadisticas/trm. Accessed January 6, 2022.

19. Ministry of Health and Social Protection. Resolution Number 8430 of 1993.

20. World Health Organization. Distribution of health spending and catastrophic spending: methodology Discuss Pap. 2005;2(1):12. 
21. Cylus J, Thomson S, Evetovits T. Catastrophic health spending in Europe: equity and policy implications of different calculation methods. Bull World Health Organ. 2018;96(9):599-609. doi:10.2471/ BLT.18.209031

22. Myint ANM, Liabsuetrakul T, Htay TT, Wai MM, Sundby J, Bjertness E. Impoverishment and catastrophic expenditures due to out-of-pocket payments for antenatal and delivery care in Yangon Region, Myanmar: a cross-sectional study. BMJ Open. 2018;8 (11):1-8. doi:10.1136/bmjopen-2018-022380

23. Zhong Z, Wei H, Yang L, Yao T, Mao Z, Sun Q. Catastrophic health expenditure: a comparative analysis of smoking and non-smoking households in China. PLoS One. 2020;15(5):e0233749. doi:10.1371/ journal.pone.0233749

24. IETS-Cinets. Guías de Práctica Clínica para la prevención, detección temprana y tratamiento de las complicaciones del embarazo, parto o puerperio. 2013. [Clinical Practice Guidelines for the prevention, early detection and treatment of complications of pregnancy, childbirth or the puerperium. 2013]

25. Miller CA. Maternal and infant care: comparisons between Western Europe and the United States. Int J Health Serv. 1993;23(4):655-664. doi:10.2190/RR4G-NTB1-L229-FVHG

26. Delvaux T, Buekens P, Godin I, Boutsen M. Barriers to prenatal care in Europe. Am J Prev Med. 2001;21(1):52-59. doi:10.1016/S07493797(01)00315-4

27. Bernal-Aguirre C, Carvajal-Sierra H, Alvis-Zakzuk NJ. Costos económicos de la infección respiratoria aguda en un Municipio de Colombia Economic costs of acute respiratory infection in a municipality of Colombia [Economic costs of acute respiratory infection in a municipality of Colombia]. Revista de La Universidad Industrial de Santander Salud. 2017;49(3):470-477. doi:10.18273/revsal.v49n3-2017005
28. Alvis-Zakzuk NJ, Díaz-Jiménez D, Castillo-Rodríguez L, et al. Economic costs of chikungunya virus in Colombia. Value Health Reg Issues. 2018;17:32-37. doi:10.1016/j.vhri.2018.01.004

29. Cartagena cómo vamos. Informe de calidad de vida 2015 [how are we doing? Quality of life report 2015]; 2015. Available from: http:/www. cartagenacomovamos.org/nuevo/wp-content/uploads/2016/07/ Presentación-ICV-2015-Cartagena-Cómo-Vamos.pdf. Accessed January 6, 2022.

30. Cartagena cómo vamos. ¿Para dónde vamos? Informe de calidad de vida 2018 [how are we doing? Where are we going? Quality of life report 2018]. Módulo pobreza; 2018. Available from: http://www.cartagenaco movamos.org/nuevo/wp-content/uploads/2019/09/Informe-Calidad-deVida-2018-Módulo-Pobreza.pdf. Accessed January 6, 2022.

31. Etikan I. Comparison of convenience sampling and purposive sampling. Am J Theor Appl Stat. 2016;5:1. doi:10.11648/j. ajtas.20160501.11

32. Sen A. ¿Por qué la equidad en salud? [Why should there be equity in health?] Rev Panam Salud Publica. 2002;11:302-309. doi:10.1590/ S1020-49892002000500005

33. Alvis-Estrada L, Alvis-Guzmán N, De La Hoz F. Gasto privado en salud de los hogares de Cartagena de Indias, 2004 [Household spending on private health care in Cartagena de Indias, 2004]. Rev Salud Publica. 2007;9(1):11-25. doi:10.1590/S0124-00642007000100003

34. Alvis-Zakzuk N, Gutierrez-Clavijo J, Castillo-Rodríguez L, et al. PIH11 out-of-pocket health expenditures related to prenatal care: evidence from Colombia, 2018. Value Health. 2020;23:S153. doi:10.1016/j.jval.2020.04.407
ClinicoEconomics and Outcomes Research

\section{Publish your work in this journal}

ClinicoEconomics and Outcomes Research is an international, peerreviewed open-access journal focusing on Health Technology Assessment, Pharmacoeconomics and Outcomes Research in the areas of diagnosis, medical devices, and clinical, surgical and pharmacological intervention. The economic impact of health policy and health systems

\section{Dovepress}

organization also constitute important areas of coverage. The manuscript management system is completely online and includes a very quick and fair peer-review system, which is all easy to use. Visit http://www.dovepress.com/testimonials.php to read real quotes from published authors. 